Revue

Revue de l'histoire des religions

de Ihistoire des religions

$3 \mid 2020$

Varia

\title{
Julien PASTEUR, Les héritiers contrariés. Essai sur le spirituel républicain au $\mathrm{XIX}^{e}$ siècle
}

Paris, Les Belles Lettres (« Essais », 22), 2018

Sylvain Milbach

OpenEdition

Journals

Édition électronique

URL : https://journals.openedition.org/rhr/10783

DOI : 10.4000/rhr.10783

ISSN : 2105-2573

Éditeur

Armand Colin

Édition imprimée

Date de publication : 1 septembre 2020

Pagination : 490-493

ISBN : 978-2-200-93327-2

ISSN : 0035-1423

Référence électronique

Sylvain Milbach, « Julien PASTEUR, Les héritiers contrariés. Essai sur le spirituel républicain au xıx siècle », Revue de l'histoire des religions [En ligne], 3 | 2020, mis en ligne le 01 janvier 2021, consulté le 06 janvier 2023. URL : http://journals.openedition.org/rhr/10783 ; DOl : https://doi.org/10.4000/rhr.10783

Ce document a été généré automatiquement le 6 janvier 2023

Tous droits réservés 


\title{
Julien PASTEUR, Les héritiers contrariés. Essai sur le spirituel républicain au $\mathrm{XIX}^{e}$ siècle
}

Paris, Les Belles Lettres (« Essais », 22), 2018

\author{
Sylvain Milbach
}

\section{RÉFÉRENCE}

Julien PASTEUR, Les héritiers contrariés. Essai sur le spirituel républicain au XIXe siècle, Paris, Les Belles Lettres (« Essais », 22), 2018, 23 cm, 512 p., 25,90 €, ISBN 978-2-251-44791-9.

1 L'ouvrage propose un parcours dans la pensée de la démocratie du XIX ${ }^{\mathrm{e}}$ siècle français et dégage une catégorie qui serait propre à ce siècle : le spirituel républicain. Il centre son approche sur une galerie d'auteurs assez hétéroclite: Maistre, Comte, Tocqueville, Michelet, Durkheim. L'expression «spirituel républicain » apparaît pour la première fois sous la plume d'Albert Thibaudet (Les idées politiques de la France, 1932) qui désigne ainsi l'élaboration d'une morale laïque, incarnée par l'école de la Troisième République. Pour Julien Pasteur, le spirituel républicain est né de la Révolution française et a eu pour fonction de reconfigurer le lien avec le passé : s'il n'était plus question d'imiter les anciens, il n'était pas possible de ne pas tenir compte du « vide " provoqué par la perte de crédit des croyances, formées par le christianisme, qui avaient assuré la cohésion de l'ancienne société. L'auteur décline le spirituel républicain sur un vaste horizon dont la ligne directrice est la pensée du social, ce qui explique la place conférée à Durkheim pour lequel « l'esprit est un fait social » (p. 385). Le spirituel républicain revêt aussi une dimension religieuse, et c'est sans doute Quinet qui résume le mieux l'intuition de l'ouvrage: "On ne déplace pas un dieu sans que cela fasse du bruit » (La Révolution, 1865). Les débats qu'il a soulevés pèsent encore sur l'idéal républicain français, d'où le titre, peu explicité d'ailleurs : Les héritiers contrariés. Ils sont résumés en conclusion, sous la forme d'un "choix impossible»: «Soit il subsiste quelque chose de religieux 
dans les sociétés contemporaines, et il faut alors travailler incessamment à s'en défaire, puisque cet archaïsme est le lieu obscur qui nous sépare d'une politique intégrale de l'autonomie; soit toute société en conserve l'empreinte fondatrice, et il faut alors apprendre à gouverner non pas contre mais avec » (p. 451).

Les auteurs convoqués par J. Pasteur pensèrent avec anxiété la disparition de l'autorité hétéronome qu'impliquait l'avènement de la démocratie: Dieu et donc les Églises (l'Église catholique, en fait) n'avaient plus la légitimité pour justifier, non seulement l'ordre social, mais ce qui le fonde - le lien de fraternité et de croyances partagées. Le spirituel républicain prétendit répondre à la généralisation de l'indifférence et de l'individualisme: comme "spiritualité ", il entendait contrebalancer le règne du matérialisme et du scepticisme. Cette approche permet de considérer la fonction du religieux en politique non sous le seul angle institutionnel et conflictuel, mais dans sa dimension sociale et anthropologique, en développant une réflexion sur la mort ( « Le spirituel républicain se résume peut-être à cela: inventer une autre interface de communication entre vivants et trépassés ", p. 328), le mal, le statut des femmes, l'influence des sciences sur les représentations du monde.

3 En commençant son ouvrage par Maistre, l'a. confère au traditionalisme philosophique un caractère matriciel non pas, évidemment, parce que celui-ci aurait été incorporé au "spirituel républicain ", mais parce qu'il a soulevé des interrogations qui forment le socle d'une "dixneuviémité » : un ordre social pensé en termes d'autorité légitimante, une réflexion centrée sur la fragmentation de l'édifice social et une critique de l'abstraction de certaines catégories révolutionnaires, comme le peuple et la nation.

4 Rappelant l'expression de Guizot, J. Pasteur fait du "gouvernement des esprits » la grande question du $\mathrm{XIX}^{\mathrm{e}}$ siècle et, en effet, les penseurs de ce siècle cherchèrent le moyen d'obtenir le consentement au pouvoir qui éviterait de nouvelles commotions : conquérir l'influence sur les esprits impliquait de susciter la croyance dans l'ordre. L'obsession des dangers provoqués par l'entrée dans une société d'opinions ne se résumait pas à la question du suffrage universel, il s'agissait - pour le spirituel républicain - de rapatrier les promesses de la félicité dans l'au-delà sur terre, dans la cité des hommes : la pensée républicaine rapportait les vertus de la transcendance dans le social. L'ouvrage dessine ainsi les contours d'un $\mathrm{xIX}^{\mathrm{e}}$ siècle inquiet dans sa conquête de la démocratie et devant l'avenir: une dimension peu prise en compte par l'historiographie.

5 L'ouvrage soulève cependant plusieurs questions, notamment méthodologiques. La première est d'ordre chronologique. J. Pasteur postule que le spirituel républicain se défait en 1848-1852 (p. 208), dans le naufrage des idéaux de la Deuxième République. En ce cas, il relève spécifiquement de l'âge romantique. Or, on peut se demander si, depuis la Profession de foi du vicaire savoyard jusqu'à la théophilanthropie, en passant par le culte de l'Être suprême, le spirituel républicain n'est pas consubstantiel à la naissance de la démocratie, plutôt qu'uniquement la conséquence de la Révolution. Surtout, on comprend mal sa postérité: quel est le lien de continuité avec la Troisième République ? Si ce régime a encensé Michelet, Quinet, il n'a pu le faire qu'au prix d'une relecture sélective de leurs œuvres. Le chapitre consacré à Durkheim tend à éluder ces difficultés en postulant que la sociologie pourrait être « le spirituel républicain parvenu à l'âge de raison " (p. 368). Si les interrogations du fondateur de la sociologie française sont placées dans la lignée de celles de Michelet, c'est plutôt une fracture qui se dessine, avec, par exemple, l'érosion de la conviction dans la force messianique du 
peuple. S'il est clair que, pour J. Pasteur, le spirituel républicain a participé à la fondation d'une science du social, on ne saisit pas bien son influence.

6 La seconde question tient au choix des auteurs, qui n'est pas vraiment expliqué et laisse de côté des personnages alors reconnus en raison de la charge «spirituelle » de leur républicanisme : Lamennais, qui fut l'efficace critique du problème de l'indifférence et dont le parcours témoigne pour le spirituel républicain ; Victor Hugo, figure exemplaire à bien des égards de ce spirituel républicain, qui ne se réduit pas à une réflexion théorique sur le social; Jules Simon, philosophe républicain spiritualiste qui n'a cessé de penser la nécessité sociale d'un corps de croyances afin de répondre aux défis existentiels de la société post-révolutionnaire. Ce serait un mauvais procès d'étoffer cette liste des absents puisque leur nombre confirmerait l'intuition fondamentale des Héritiers contrariés. Néanmoins, le choix opéré pose problème dans la mesure où l'a. présente l'existence d'un spirituel républicain comme une catégorie distinctive d'une pensée politique. Or, force est d'admettre, qu'à partir d'un même fond d'interrogations de nature existentielle et politique, les constructions élaborées et les moyens d'atteindre «l'harmonie » sociale couvrent une large palette d'analyses et de systèmes. Les travaux qui ont mis en valeur la vigueur des " hétérodoxies romantiques» (Paul Bénichou ou Henri Desroche), ou l'historiographie anglo-saxonne (Franck-Paul Bowman ou Donald Charlton) auraient ainsi pu être convoqués. Cet élargissement de la focale est susceptible de modifier, et de renforcer, l'acception du spirituel car il le teinte d'une « religiosité » que l'auteur évacue. C'est pourtant là que réside le refoulé de l'histoire des gauches et d'une généalogie de l'idée républicaine. Par ailleurs, il existe aussi, notamment parmi les leaders "républicains» de la Restauration et de la Monarchie de Juillet, des figures étrangères à ce type de spéculations: le spirituel républicain n'est sans doute qu'une forme de la tradition républicaine.

7 L'auteur fait aussi bon marché de l'emprise socio-culturelle des Églises au XIx siècle. À part quelques notations à propos de Tocqueville, le catholicisme est hors champ, alors même qu'il constitue, pour les auteurs étudiés, un obstacle au développement de la République. Il est difficile de souscrire à l'affirmation suivant laquelle «il fallait repenser l'héritage indépendamment des sources monothéistes»(p.129), pas plus qu'on ne peut admettre que l'âme disparaisse quasiment du lexique des auteurs postrévolutionnaires (p. 384). En fait, la question du rapport au christianisme ne réside pas dans son inexorable disparition, que peu d'auteurs ont alors postulée, mais plutôt dans la capacité de recycler la culture chrétienne en la dégageant, non seulement de ses attendus politiques, mais de dogmes devenus insupportables. Sur ce point, l'a. perd de vue la dimension anthropologique. Il semble considérer que la déprise du christianisme (du catholicisme ?) est accomplie, ce qui le conduit à une sécularisation radicale de la pensée des auteurs. Au final, l'occultation de la « religiosité » de ce temps rend un peu incertain, car trop indéfini, l'usage des dénominations « spirituel » et « religieux ».

8 À certains égards, avec son cheminement dans le spirituel républicain, Julien Pasteur refait le chemin parcouru par Philippe Muray (Le XIX ${ }^{e}$ siècle à travers les âges), mais par un autre versant. Alors que celui-ci voyait surtout dans un (très) long $\mathrm{xIX}^{\mathrm{e}}$ siècle une "spiritualité » déviante, une pathologie irrationnelle, et qu'il portait sur lui les jugements les plus dépréciatifs, l'a. des Héritiers contrariés fait un pari plus empathique en valorisant la profondeur de la réflexion sur la société démocratique. L'un et l'autre versant sont bien les deux faces d'un même siècle. 


\section{AUTEURS}

\section{SYLVAIN MILBACH}

Université de Savoie. 